\title{
Preschool Social and Cognitive Behaviors: The Southern Illinois Twins
}

\author{
Lisabeth F. DiLalla \\ Department of Family and Community Medicine, Southern Illinois University School of Medicine, USA
}

\begin{abstract}
The Southern Illinois Twins registry consists of a small group of twins from the southern Illinois area and some areas in Missouri and Kentucky, as well as siblings of twins and singletons who have been involved in the study. The current project has as its primary focus the identification of variables that predict aggressive and prosocial behaviors in preschoolers, especially to explore the etiology of individual differences in aggressive and prosocial behaviors from a behavior genetic perspective. Twins are tested yearly within months of their birthdays, from ages 1 year to 5 years. Siblings are tested at 5 years of age. At ages 1-4 years, children are tested on a cognitive battery and mother-child interactions are videotaped. At 5 years, children engage in a peer play situation in the lab. Results thus far suggest that aggression during play in the lab shows genetic influence, corroborating earlier parent rating studies.
\end{abstract}

Peer social competence in the preschool years has been shown to relate to the quality of later peer interactions (Crick \& Dodge, 1994; Dodge, 1983), and these in turn are predictive of dysfunctional behaviors such as delinquency (Farrington, 1991) in later childhood and possibly adulthood. Recent research on aggression in children has demonstrated a genetic influence on this behavior (e.g., Cadoret et al., 1997; Deater-Deckard \& Plomin, 1999; Edelbrock et al., 1995; Eley et al., 1999). However, this research primarily has involved adolescents and has relied on parent ratings of aggression (Cadoret et al., 1997; Miles \& Carey, 1997) rather than on observed child behaviors. Equally important are the genetic influences on cooperative behaviors in children, as these represent an alternate behavior to aggression during normal peer interactions. However, few studies have assessed aggression and cooperation during play using observational measures in preschoolers, and we are not aware of any studies of genetic influences on aggressive or cooperative peer play in preschoolers besides the present study.

In addition to assessing peer interactional styles, there are two behaviors on which this project also focuses that may predict early peer interactional styles as well as later delinquency. The first is cognitive ability, because intelligence has been linked to delinquency (Lynam et al., 1993). The second is early mother-child interactions, which also may be related to the child's cognitive ability because of the degree to which parents can enhance rather than discourage children's exploratory behaviors (Berlin et al., 1995; Landry et al., 1998), possibly reflecting gene-environment correlation between children's inherited intelligence and the parental environment they elicit (DiLalla, 2000).

\section{The Southern Illinois Twins Data Set}

The Southern Illinois Twins registry comprises twins born since 1988. This is an on-going and growing registry of a small group of twins. One advantage of the small number of regional twin families is that we have been able to assess children in the lab rather than having to make use of mailed questionnaires. Thus, some unique data on early cognitive abilities and peer interactions are available in this sample, as described below.

\section{Recruitment Process}

For the first several years (1993-1998), local birth records were accessed, as were birth records in a nearby southern county in Missouri. All twins' names were recorded and cross-referenced by death, and families were sent letters inviting them to join the registry. However, there were very few twins born per year in this region (approximately 30 pairs per year) and the response rate to these letters was poor, so this did not yield a large number of twin families. Additionally, the state of Illinois has disallowed researchers' access to birth records, so twins can no longer be ascertained in this manner. Twins also have been recruited through various other methods, including: visiting the local Mothers of Twins Club, a small group that yielded several more families; recruiting families when research assistants come across them in public; advertising on the lab web page (accessible at http://www.siumed.edu/playlab); sending letters to or calling families that could be located after the birth of their twins was announced in the local newspaper; and identifying twin families who are known to parents already in the study. Thus far, 131 twin pairs have been recruited (52 male pairs, 48 female pairs, 31 opposite-sex pairs).

In addition to testing twins, we also test siblings of children (both twins and singletons) who have already been tested in the lab. All siblings are tested at age 5 years on the 5-year-old protocol. Thus far, 47 siblings pairs have been tested (10 male pairs, 19 female pairs, 18 oppositesex pairs).

\section{Methodology}

Twins are tested in a campus laboratory every year within two months of their birthdates. At ages 1 through 4 years,

Address for correspondence: Dr. Lisabeth F. DiLalla, Department of Family and Community Medicine, Mail Code 6503, Southern Illinois University School of Medicine, Carbondale, Illinois, 629016503 USA. Email: ldilalla@siu.edu 
Table 1

Testing Protocol

\begin{tabular}{|c|c|c|c|c|c|c|c|c|}
\hline Age & $\begin{array}{l}\text { Piagetian } \\
\text { Tasks }\end{array}$ & $\begin{array}{c}\text { Fantasy } \\
\text { Play }\end{array}$ & $\begin{array}{l}\text { Mother-Twins } \\
\text { Interaction }\end{array}$ & $\begin{array}{l}\text { Peer } \\
\text { Play }\end{array}$ & $\begin{array}{c}\text { Child Ratings } \\
\text { by Parent }\end{array}$ & $\begin{array}{c}\text { Parent } \\
\text { Personality }\end{array}$ & $\begin{array}{l}\text { Teacher } \\
\text { Follow-up }\end{array}$ & $\begin{array}{l}\text { Parent/Child } \\
\text { Follow-up }\end{array}$ \\
\hline 1 year & $X$ & $X$ & $X$ & & & & & \\
\hline 2 years & $x$ & $x$ & $X$ & & & & & \\
\hline 3 years & $x$ & & $x$ & & & & & \\
\hline 4 years & $x$ & & $x$ & & & & & \\
\hline 5 years & & & & $x$ & $X$ & $x$ & & \\
\hline 9-13 years & & & & & & & $x$ & $x$ \\
\hline
\end{tabular}

they are tested on a battery of cognitive tasks and they conclude with a mother-child interaction session. At age 5, they engage in a peer play situation. These are summarized in Table 1 and are described in more detail below.

The current project has as its primary focus the identification of variables that predict aggressive and prosocial behaviors in preschoolers, especially to explore the etiology of individual differences in aggressive and prosocial behaviors from a behavior genetic perspective. Specifically, the behaviors of interest are those engaged in by preschool children when interacting with unfamiliar peers in an unfamiliar setting. To this end, twins and siblings are tested when they are 5 years old ( \pm 2 months). Children are brought to a laboratory playroom and are allowed to play freely, one at a time, with a child who is matched with respect to sex and age. Each pair of children (one twin or a sibling, and one singleton) plays for 20 minutes; the play session is videotaped for later behavioral coding. Parents also complete several questionnaires about their children, including zygosity assessment, the Behavioral Style Questionnaire (BSQ; McDevitt \& Carey, 1978), the Child Behavior Checklist (CBCL; Achenbach, 1991a), and a daycare history, as well as a questionnaire about family demographics and two about their own personality - the Aggression subscale of the Multidimensional Personality Questionnaire (MPQ; Tellegen, 1982) and the Adjective Checklist (Saucier, 1994). Table 2 summarizes the specific information gathered at each age from parental questionnaires and laboratory testing.

Table 2

Specific Measures Currently Administered at Each Age

Cognitive

Ages $1 \& 2$ years

Ages $3 \& 4$ years

Fantasy

Ages $1 \& 2$ years

Mother-Twins Interaction Age 1 year

Age 2 years

Age 3 years

Age 4 years

Peer Play

Age 5 years

Parent Questionnaires about Children and Family

Age 1-4 years

Age 5 years

Age 5 years
Piagetian $A$-not-B error. a small object is hidden under a cup, then displaced and re-hidden, and the child must locate the object; Self-awareness: child is held in front of a mirror and told to find a toy that is being held above her/his head.

Piagetian conservation of liquid, mass, length, and number; Matrix Classification of items by sorting items into two-dimensional groups; Hierarchical Classification by demonstrating an understanding of shared group dimensions ("Are there more bears or more animals?"); the Memory sub-test of the Stanford-Binet.

Child is asked to imitate the tester, who pretends to talk into a plastic telephone, then into a plastic banana (a more cognitively complex pretend task). Then child is asked to imitate the tester, who pretends to drive a plastic block as though it were a car.

Mother teaches children to sort plastic rings by shape - circles, squares, and triangles

Mother teaches children to sort plastic rings by both shape and color

Mother teaches children to classify 2 rows of pictures on 2 dimensions (e.g., shape and color)

Mother teaches children to classify 4 rows of pictures on 2 dimensions

Child plays with an unfamiliar child, same sex and age, for 20 minutes in the lab playroom. Play is videotaped and later coded for inhibition, aggressive behaviors, prosocial behaviors, commanding behaviors, rough and tumble play.

Zygosity ratings (taken from the Nichols \& Bilbro, 1966, zygosity questionnaire — reported accuracy 95\%) family information (e.g., SES, other siblings)

Zygosity ratings; family information; child temperament (BSQ; McDevitt \& Carey, 1978); child behavior problems (CBCL; Achenbach, 1991a); daycare history parent questionnaires about their own personality.

Aggression subtest of the MPQ (Tellegen, 1982); Adjective Checklist (Saucier, 1994) 
At ages 1 through 4 years, twins are tested on a battery of cognitive tasks (see Table 2). At ages 1 and 2 years, twins are also administered several fantasy play tasks where the child must imitate use of a pretend toy. Finally, the child is placed in front of a mirror and must locate an object held above his or her head, demonstrating self-awareness. At ages 3 and 4 years, the tasks are more complex. The cognitive tasks include Piagetian conservation (Piaget \& Szeminska, 1952), matrix and hierarchical classification (DeHart et al., 2000), and the Memory sub-test of the Stanford-Binet Intelligence Scale, 4th Edition (Thorndike et al., 1986). At all four ages, the sessions conclude with a 10-minute segment wherein one parent (usually the mother) and both twins sit together on the floor and the parent is asked to teach the children a difficult task. This interaction is videotaped and later coded for mother-child interactional styles.

\section{Results}

Preliminary analyses on the 5-year-old play data have shown that both observational and parent-rating data demonstrate the existence of a heritable component to aggressive behaviors (DiLalla, 1999). Intra-pair correlations were calculated for identical twins, fraternal twins, and siblings tested at the same age for an observational measure of aggression (grabbing a toy from the other child) and a total aggression measure (grabbing a toy plus parent ratings of aggression from the CBCL and BSQ). The $\mathrm{MZ}$ twins were much more similar to each other $(r=.64$ for Grab Toy, $r=.91$ for Total Aggression) than were DZ twins $(r=-.09$ for Grab Toy, $r=$ .52 for Total Aggression) or siblings ( $r=.16$ for Grab Toy, $r=$ .34 for Total Aggression) (DiLalla \& Gehlbach, 2000). These influences must be considered in addition to environmental ones in developing a full understanding of children's abilities to interact appropriately with peers in novel situations. This clarifies earlier results (Dodge et al., 1990) showing that children maintain similar peer interactions across situations even when they move into new peer groups. Novel peer situations are important ones for children in establishing themselves in new situations, such as a new school or new neighborhood.

\section{Future Plans}

We currently are engaged in a follow-up study of all families who were tested between 1993 and 1996, including twin families and singleton families who have been tested in the Play Lab. Children's current teachers are asked to complete the Teacher's Report Form (TRF; Achenbach, 1991b), the Teacher Checklist of Peer Relationships (Dodge, 1986), and the Student-Teacher Relationship Scale (STRS; Pianta, 1992). Additionally, questionnaires will be sent to the parents and children to investigate non-shared environment factors (e.g., dissimilar perceptions of parenting) and to investigate reciprocity in parent-child relationships. We hope to predict behavioral problems as well as interpersonal competencies from our preschool cognitive and peer play data.

\section{References}

Achenbach, T. M. (1991a). Manual for the Child Behavior Checklist/4-18 and 1991 Profile. Burlington, VT: University of Vermont Department of Psychiatry.
Achenbach, T. M. (1991b). Manual for the Teacher's Report Form and 1991 Profile. Burlington, VT: University of Vermont, Department of Psychiatry.

Berlin, L. J., Brooks-Gunn, J., Spiker, D., \& Zaslow, M. J. (1995). Examining observational measures of emotional support and cognitive stimulation in black and white mothers of preschoolers. Journal of Family Issues, 16, 664-686.

Cadoret, R. J., Leve, L. D., \& Devor, E. (1997). Genetics of aggressive and violent behavior. Anger, Aggression, and Violence, 20, 301-322.

Crick, N. R., \& Dodge, K. A. (1994). A review and reformulation of social information-processing mechanisms in children's social adjustment. Psychological Bulletin, 115, 74-101.

Deater-Deckard, K., \& Plomin, R. (1999). An adoption study of the etiology of teacher and parent reports of externalizing behavior problems in middle childhood. Child Development, 70, 144-154.

DeHart, G. B., Sroufe, L. A., \& Cooper, R. G. (2000). Child development: Its nature and course (4th ed.). Boston: McGraw Hill.

DiLalla, L. F. (1999, April). Biological and environmental pathways to aggressive behavior in children. Paper presented to the Society for Research in Child Development, Albuquerque, NM.

DiLalla, L. F. (2000). Development of intelligence: Current research and theories. Journal of School Psychology, 38, 3-7.

DiLalla, L. F., \& Gehlbach, L. N. (2000, April). Preschooler aggression during free play shows genetic influences. Poster presented to the Conference on Human Development, Memphis, TN.

Dodge, K. A. (1983). Behavioral antecedents of peer social status. Child Development, 54, 1386-1399.

Dodge, K. A. (1986). A social information processing model of social competence in children. In M. Perlmutter (Ed.), Eighteenth Annual Minnesota Symposium on Child Psychology (pp. 77-125). Hillsdale, NJ: Erlbaum.

Dodge, K. A., Coie, J. D., Pettit, G. S., \& Price, J. M. (1990). Peer status and aggression in boys' groups: Developmental and contextual analyses. Child Development, 61, 1289-1309.

Edelbrock, C., Rende, R., Plomin, R., \& Thompson, L. A. (1995). A twin study of competence and problem behavior in childhood and early adolescence. Journal of Child Psychology and Psychiatry, 36, 775-785.

Eley, T. C., Lichtenstein, P., \& Stevenson, J. (1999). Sex differences in the etiology of aggressive and nonaggressive antisocial behavior: Results from two twin studies. Child Development, 70, $155-168$.

Farrington, D. P. (1991). Childhood aggression and adult violence: Early precursors and later-life outcomes. In D. J. Pepler \& K. $\mathrm{H}$. Rubin (Eds.), The development and treatment of childhood aggression (pp. 5-29). Hillsdale, NJ: Erlbaum.

Landry, S. H., Smith, K. E., Miller-Loncar, C. L., \& Swank, P. R. (1998). The relation of change in maternal interactive styles to the developing social competence of full-term and preterm children. Child Development, 69, 105-123.

Lynam, D., Moffitt, T. E., \& Stouthamer-Loeber, M. (1993). Explaining the relation between IQ and delinquency: Class, race, test motivation, school failure, or self-control? Journal of Abnormal Psychology, 102, 187-196.

McDevitt, S. C., \& Carey, W. B. (1978). The measurement of temperament in 3-7 year old children. Journal of Child Psychology and Psychiatry, 19, 245-253. 
Miles, D. R., \& Carey, G. (1997). Genetic and environmental architecture of human aggression. Journal of Personality and Social Psychology, 72, 207-217.

Nichols, R. C., \& Bilbro, W. C. (1966). The diagnosis of twin zygosity. Acta Geneticae Medicae et Gemellologiae, 16, 265-275.

Piaget, J., \& Szeminska, A. (1952). The child's conception of number. NY: Basic Books.

Pianta, R. C. (1992). Student-Teacher Relationship Scale. Unpublished, University of Virginia, Charlottesville, VA.
Tellegen, A. (1982). Brief manual for the Multidimensional Personality Questionnaire. Unpublished manuscript, University of Minnesota.

Thorndike, R., Hagen, E., \& Sattler, J. (1986). Guide for administering and scoring the fourth edition Stanford-Binet Intelligence Scale. Chicago: Riverside.

Saucier, G. (1994). Mini-markers: A brief version of Goldberg's unipolar big-five markers. Journal of Personality Assessment, 63, 506-516. 